\title{
A educação infantil na agenda A definição da política pública
}

Fabiana Silva Fernandes*

RESUMO: O artigo é uma reflexão sobre a educação infantil como objeto de política pública, promovendo uma discussão sobre a agenda política, que envolve diferentes setores da sociedade, além das instâncias governamentais. $\mathrm{O}$ texto está organizado de modo a definir brevemente a política pública e o papel dos diferentes setores da sociedade para tratar da educação infantil como política pública. Finalmente, discute concepções restritas divulgadas no discurso político e acadêmico e aponta desafios para a implementação da política de educação a crianças de 0 a 5 anos.

Palavras-chave: Educação infantil. Políticas públicas. Política educacional. História da Educação.

\section{Child education on the agenda}

The definition of public policy

\begin{abstract}
The article is a reflection on the education of children as an object of public policy, promoting a discussion about the political agenda, which involves different sectors of society, in addition to governmental instances. The text is organized in such a way as to briefly define public policy and the role of different sectors of society in dealing with child education according to public policy. Finally, it discusses restricted conceptions divulged in the political and academic discourse and points out challenges to the implementation of education policy for children from 0 to 5 years.
\end{abstract}

* Doutora em Educação Escolar pela Universidade Estadual Paulista Júlio de Mesquita Filho. Foi professora da Pontífícia Universidade Católica, de Campinas e, atualmente, é pesquisadora da Fundação Carlos Chagas. São Paulo, SP - Brasil. E-mail: <fsfernandes@fcc.org.br>. 
Keywords: Child education. Public policy. Educational politics. History of education.

\section{La educación infantil en la agenda}

La definición de la política pública

RESUMEN: Este artículo consiste en una reflexión sobre la educación infantil como objeto de política pública, promoviendo una discusión sobre la agenda política que implica a diferentes sectores de la sociedad, además de las instancias gubernamentales. En primer lugar, el texto define brevemente la política pública y el papel de los diferentes sectores de la sociedad al tratarse la educación infantil como política pública. Finalmente, discute conceptos limitados divulgados en el discurso político y académico y señala los retos a la implementación de la política de educación para niños/as de 0 a 5 años.

Palabras clave: Educación infantil. Políticas públicas. Política educativa. Historia de la Educación.

\section{L'éducation infantile dans l'agenda}

La définition de la politique publique

RÉSUMÉ: Cet article est une réflexion sur l'éducation infantile comme objet de politiques publiques, facilitant une réflexion sur l'agenda politique qui implique différents secteurs de la société, en plus des instances gouvernementales. Le texte est organisé de manière à définir succintement le rôle des différents secteurs de la société relativement à l'éducation infantile comme politique publique. Enfin, y sont discutées les conceptions limitées diffusées par le discours politique et académique et indiqués les défis pour l'implantation de politique éducative pour l'enfant de 0 à 5 ans.

Mots-clés: Education infantile. Politiques publiques. Politique éducationelle. Histoire de l'éducation. 


\section{Introdução}

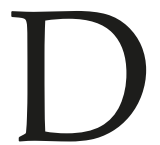

o ponto de vista conceitual, uma política pública pode ser definida como um conjunto de decisões diante da necessidade de manter ou modificar uma realidade, em um ou mais setores da sociedade, como a economia, a assistência social, a educação e a saúde. Há diferentes enfoques, modelos e estratégias para a formulação e a implementação de políticas públicas, como, por exemplo, as políticas de caráter universal e as políticas focalizadas, adotadas com bastante intensidade desde o contexto dos anos de 1980, quando os estados latino-americanos enfrentavam uma crise fiscal sem precedentes.

O propósito do texto não é apresentar modelos de formulação e implementação das políticas, mas promover uma reflexão sobre os motivos que fazem com que determinados problemas da sociedade ganhem visibilidade e sejam submetidos à agenda governamental. Para esse intento são resgatados alguns momentos da história da educação infantil, de modo a explicitar a forma como os diferentes interesses sociais se confrontam e se conformam nas agendas políticas.

O texto está organizado no sentido de definir brevemente a política pública e o papel dos diferentes setores da sociedade na configuração das políticas, para em seguida, tratar da educação infantil como política pública no contexto atual.

A perspectiva é a de que a motivação para a formulação de uma política pública é o embate em torno de concepções e interesses no âmbito das instituições governamentais, mas também na sociedade civil. As decisões em torno das políticas são marcadas por relações de interesse, disputas de classes e de grupos e movimentos sociais e indivíduos afetados pela política pública. Isso significa que o Estado possui autonomia relativa na formulação, mas também na implementação e na execução das políticas públicas, uma vez que é permeada por influências externas (SOUZA, 2006).

\section{Políticas públicas e educação infantil}

As políticas sociais, no âmbito das políticas públicas, são direcionadas para a garantia de direitos e para a manutenção do bem-estar da população e têm como propósito o atendimento de demandas sociais. Mas, nem todas as demandas e necessidades se tornam objeto da política pública. Precisam entrar na agenda política, submetendo-se às instâncias de poder e de administração do Estado que as condicionarão em leis, políticas, programas, projetos e ações. Alvo de mobilizações sociais e fruto de necessidades imperativas de membros da sociedade, as demandas sociais, antes de se tornarem parte da agenda política, vão se configurando historicamente, no processo social, até se tornarem 
um problema social e, portanto, alvo da intervenção estatal. (PARADA, 2006; SARAVIA, 2006; TORRES, 2004; FERNANDES, 2014).

O Estado, por conseguinte, não é o detentor das mudanças, das transformações e a sociedade civil, em particular as classes populares, não é mero agente executor de políticas elaboradas pelo Estado. À definição de uma agenda, no âmbito da política pública, antecedem as necessidades sociais, que transparecem nas reivindicações de movimentos sociais e nos processos de participação política das diversas classes.

Resultado das contradições sociais, as necessidades emergem como bandeira de luta, consubstanciando-se em direitos e mobilizando processos, tendências e significados na regulamentação das leis e na implantação de políticas. As reivindicações sociais são a expressão coletiva das necessidades, exibindo as contradições e trazendo elementos novos na sociedade. Nesse processo, o Estado possui papel estratégico na viabilização dos recursos para a satisfação das necessidades (PARADA, 2006; SARAVIA, 2006; TORRES, 2004; ESPORATI, 1988).

A educação infantil é um elemento do conjunto das necessidades sociais que vão se constituindo historicamente e, ao longo da história, vem assumindo diferentes configurações em sua finalidade, na sua estrutura e funcionamento, conforme as mudanças no quadro das relações sociais, como, por exemplo, as mudanças no sistema produtivo, a diversificação do mercado de trabalho, a incorporação da mulher como mão-de-obra: são mudanças que criam novas necessidades.

No contexto do ingresso da mulher no mundo produtivo, por exemplo, a creche foi reivindicada nas lutas populares:

\begin{abstract}
Essa inserção não foi acompanhada de uma correspondente constituição de uma infraestrutura mínima que lhe possibilidade desenvolver as "novas" atribuições. Neste sentido, houve um agravamento na situação da mulher que sempre teve um papel de subordinação e de objeto de opressão na sociedade. Por outro lado, a inserção no mercado de trabalho permitiu-lhes uma tomada de consciência dessa opressão, e forneceu-lhes condições objetivas de organização e luta por seus direitos. Algumas destas lutas dizem respeito à maternidade, sexualidade, etc. Outras dizem respeito a questões gerais da sociedade, como, por exemplo, a questão da creche. A creche não é um problema específico da mulher à medida em quediz respeito a obrigações que são, além de outros membros da família, também do Estado (o qual recebe impostos para gerir equipamentos públicos); e das empresas, além de ser também da nação, uma vez que diz respeito à própria formação das gerações futuras. (GOHN, 1985, p. 107)
\end{abstract}

Nos anos de 1970, assistiu-se ao ressurgimento da preocupação do poder público com a situação da criança pequena, isso porque a reivindicação "por creche espalhou-se, penetrando na agenda política” (SCAVONE, 2011, p.4). Essa preocupação refletiu-se na criação de alguns programas setoriais, no entanto, havia a falta de definição de competências entre os entes federativos e os órgãos públicos e, portanto, a sobreposição de ações (POPPOVIC et. al., 1983). Por conseguinte, ao longo dos anos de 1970 e 1980, as 
instituições de atendimento a crianças de 0 a 6 anos foram alvo de programas constituídos por ações fragmentadas e que se caracterizavam por diferentes tendências, em que se enfatizavam, as ações relacionadas a higiene e a saúde; preocupações com assistência social e ações do âmbito educacional.

Nesse período, havia diversos tipos de atendimento por parte do poder público e as creches e pré-escolas atendiam, respectivamente, crianças de 0 a 6 anos e crianças na faixa etária dos 3 ou 4 anos até 6 anos. Os municípios tomaram diferentes iniciativas para o atendimento das demandas, uma vez que estavam mais perto da pressão das famílias e grupos sociais (POPPOVIC, 1983).

Até 1963, em São Paulo, as creches pertenciam a órgãos estaduais que cuidavam da questão do menor (GOHN, 1985). Alterações nas áreas de atuação entre o Serviço Social Municipal e o Serviço de Menores do Estado permitiram ao município iniciar o atendimento em creches, mediante a criação de convênios com entidades sociais.

Em 1967, foi criada a Secretaria do Bem-Estar Social, que inaugurou as primeiras creches municipais em São Paulo e, em 1971, defendia-se uma política de expansão das matrículas para as crianças de 0 a 6 anos, a criação de novos convênios, a instalação de nova rede municipal de centros infantis, entre outras medidas (GOHN, 1985). Definidas como unidades de atendimento às crianças, as creches tinham por finalidade promover o desenvolvimento biopsicossocial, mediante o acompanhamento da saúde e nutrição e a implementação de serviços na área de serviço social e psicopedagogia.

As iniciativas das prefeituras municipais para atender a demanda por creches esbarravam nos limites impostos pela legislação, uma vez que o município, antes da Constituição de 1988, não era autônomo e sua capacidade para legislar e formular políticas públicas era restrita até mesmo no âmbito financeiro pois não tinha orçamento próprio. Havia o embate entre as esferas de governo estadual e municipal em torno das competências e responsabilidades de cada ente federativo nas políticas públicas, uma vez que os encargos sociais eram de responsabilidade dos estados (SCAVONE, 2011; SPOSATI, 1988).

Isso significa que a atuação municipal respondia, de alguma forma, à pressão das demandas populares, indicando, portanto, que a definição da agenda política e a formulação das políticas públicas não seguem o fluxo unidirecional das instâncias governamentais para a população, pois são o resultado de embates, interesses e necessidades sociais que se espraiam em todas as direções e, paulatinamente, no processo de disputas, e dadas as condições históricas, sociais, econômicas do momento vão tomando uma direção e se conformando nos limites político-institucionais que definem a estrutura e o funcionamento do Estado.

$\mathrm{O}$ atendimento restrito e as mudanças no sistema produtivo mobilizaram os diversos setores sociais em favor da educação infantil, em particular das creches. Nas reivindicações, estavam na pauta não somente a ampliação do acesso, mas também a garantia de 
um ambiente seguro e adequado para a educação das crianças. No decorrer das mobilizações, a creche adquire novo significado social, como direito da população. "A creche passa a ser vista como um equipamento de bem-estar comunitário para assistir a criança de 0 a 6 anos e 11 meses, pertencente à família de baixa renda, cuja mãe ou responsável trabalhe fora do lar" (GOHN, 1985, p. 162)

Em São Paulo, as entidades e associações feministas que reivindicavam creches e cuja ação, ao longo do decênio, culminou com o Movimento de Luta por Creches, pediam creche pública, financiada pelo Estado e empresas, que contivesse uma orientação pedagógica em que a participação dos pais fosse prevista (GOHN, 1985). Esse movimento tomou forma no final de década de 1970 e surgiu da confluência de vários tipos de organização, além dos movimentos feministas. Eram movimentos sociais urbanos, que vinham ganhando força desde o início de 1970, em torno da reivindicação por melhores condições de vida (CAMPOS, 1988)

Com o ressurgimento dos movimentos sociais urbanos, a concepção de creche foi recuperada e depurada da estigmatização de um depósito de crianças, de asilo ou abrigo para crianças abandonadas (POPPOVICH, 1983). Portanto, já havia toda uma discussão sobre as finalidades da creche no cuidado e na educação das crianças. Essa consciência sobre o papel da creche possui relação estreita com a preocupação com a qualidade do serviço oferecido e contribuiu para que esforços fossem envidados na definição de padrões de qualidade, possibilitando à educação infantil uma característica que lhe é peculiar: o cuidado com o ambiente educativo.

E foi na organização do Movimento de Luta por Creches, confrontando-se com o Estado e suas tentativas de cooptação, que a creche foi reivindicada como direito da família, dos trabalhadores, para ser construída em todos os bairros e locais de trabalho. Essa bandeira abriu espaços de luta e deu visibilidade para um problema social, que teve que ser assumido como política pública, dadas as condições de vida da massa de trabalhadores e as necessidades de reprodução da própria atividade econômica.

\section{O do direito da criança a educação}

Durante o processo de reivindicação pela creche, as necessidades sociais em torno do espaço físico para os filhos de trabalhadores, ao mesmo tempo em que se tornam um problema social, vão adquirindo novos significados, com a agregação de outros grupos sociais nesse processo e a transição da ditadura militar para a democracia. Paulatinamente, as demandas ampliam o foco sobre a necessidade de providenciar espaço físico da creche para a necessidade de garantir a educação infantil como um direito das crianças de 0 a 6 anos. 
A crescente importância que vem sendo conferida à educação infantil, desde a década de 1970, relaciona-se à mudança no papel da mulher no mundo produtivo e às transformações nos arranjos familiares, mas vai se conjugando com outros motivos, como a crescente urbanização, os avanços das pesquisas sobre o desenvolvimento infantil, em que se aponta a importância dos primeiros anos de vida para o desenvolvimento físico, afetivo, cognitivo e social, e, por fim, o reconhecimento dos direitos da criança no plano internacional (Campos, 2008). Todos esses fatores decorrem de profundas mudanças econômicas, políticas, e sociais que, no contexto da Constituinte de 1987, foram reclamados pelos diferentes grupos, entidades e movimentos compromissados com a educação, com os valores democráticos e com os direitos sociais.

Na década de 1980, houve a mobilização intensa de entidades, partidos políticos, sindicatos, educadores e estudantes nas Conferências Brasileiras de Educação, realizadas no contexto da Assembleia Nacional Constituinte. Esse amplo movimento da sociedade lutava por uma educação pública e de qualidade.

Já no âmbito da educação infantil, não havia consenso, no meio educacional, sobre a inclusão das creches na educação. Mas, o esforço de grupos comprometidos com a educação do pré-escolar, entre eles o Grupo de Trabalho de Educação Pré-Escolar, da Associação Nacional de Pós-Graduação (Anped) e movimentos de mulheres (CAMPOS 1986), contribuiu para que a educação infantil fosse definida como direito da criança.

Nesse contexto, também foi organizada uma comissão interministerial, denominada Comissão Nacional Criança e Constituinte, que reuniu quantidade expressiva de organizações sociais, com o propósito de construir uma proposta para a criança na nova Carta Constitucional (NUNES, CORSINO, VITAL, 2011).

Resulta que a Constituição Federal de 1988 congregou valores e expectativas das mobilizações em torno da educação e a creche, juntamente com a pré-escola, adquiriu novo status, como direito social e educacional. A Constituição Federal deu o impulso inicial para que as creches, que antes pertenciam às secretarias de assistência social e saúde, fossem incorporadas pelo setor educacional, uma vez que a educação infantil foi definida como composta por creches e pré-escolas.

Em 1996, a promulgação da Lei de Diretrizes e Bases da Educação Nacional (Lei 9394/96) infunde uma nova perspectiva de organização da educação infantil, uma vez que foi definida como primeira etapa da educação básica, devendo ser oferecida pelos municípios.

Nesse contexto, iniciou-se um processo de expansão das instituições de educação infantil que tem sido acompanhado por uma rede difusa de movimentos sociais e entidades compromissadas com a criança e a educação infantil, mas que tem tido ao longo desse percurso papel político importante, como os fóruns de educação infantil. Espalhados por diferentes estados e municípios, os fóruns são instâncias que congregam diferentes interlocutores, vinculados a sindicatos, entidades sociais, associações 
de profissionais da educação e que catalisam esforços da sociedade civil para a defesa da educação infantil. Os fóruns tiveram papel imprescindível no destino de recursos financeiros para creches e pré-escolas, mediante o Fundo de Manutenção e Desenvolvimento da Educação Básica e de Valorização dos Profissionais da Educação (Fundeb).

Todas essas conquistas foram muito importantes e têm uma série de implicações, na medida em que a educação infantil passou a compor, fundamentalmente, as políticas municipais de educação e a se submeter às normas e à organização do setor de educação e não mais da assistência, cuja lógica de atendimento fundamentava-se em critérios sociais.

A transição das instituições de educação infantil que estavam subordinadas a outras secretarias que não às de Educação, não foi tarefa fácil e instantânea, exigindo um esforço centralizado e conjunto do Ministério da Educação, do Ministério do Desenvolvimento Social e Ministério da Fazenda para o mapeamento das instituições, dos programas orçamentários, enfim, das ações dos setores que, muitas vezes, se sobrepunham, principalmente no repasse de verbas. Essa empreitada foi realizada por um GT instituído em 2007, que fez um diagnóstico para orientar o processo de transição das instituições vinculadas à Assistência Social para a Educação. Em 2009, foi concluído o processo de transição da gestão da rede de creches do Ministério do Desenvolvimento Social para o Ministério da Educação, consolidando o entendimento de que a creche e a pré-escola não são serviços de assistência (NUNES et al., 2011)

Isso não significa que, tal como proclamado no discurso educacional, a educação infantil deixou de ser assistencialista para assumir sua vocação educacional. Esse tipo de afirmação representa uma visão simplificada, ou mesmo linear, da realidade, que desconhece ou ignora o movimento histórico de constituição dessas instituições (KUHLMANN, 1998). A educação infantil, em especial as creches, nunca deixou de ter um papel educativo. A difusão das instituições de educação infantil pelos serviços de assistência social, desde o século XIX, foi motivada pela necessidade de se educar moralmente e intelectualmente a população pobre (KUHLMANN JR, 1998). Imbuídas do espírito moderno daquela época, decorrente das descobertas científicas, as iniciativas de implementação dessas ações traziam uma concepção de educação moralista e civilizatória, divergente do que se entende por educação atualmente, mas, assim mesmo, havia propósito educativo. A negação desse caráter educacional das instituições associadas a entidades ou propostas assistenciais dá margem a uma concepção ingênua de educação, "como se educar fosse algo [somente] positivo, neutro ou emancipador" (KUHLMANN JR, 1998, p.73).

Outra implicação dessa concepção restrita de educação infantil é a adoção de uma abordagem que enfoca conteúdos para o desenvolvimento da dimensão cognitiva, em detrimento de outros atributos e necessidades da criança. A focalização em processos de alfabetização, por exemplo, e as negligências com a dimensão de cuidado legitimam e vão ao encontro de uma perspectiva escolarizante de educação infantil, defendida 
por agências internacionais de financiamento e economistas comprometidos com uma dimensão economicista da educação. Fundada no discurso que enxerga apenas os benefícios futuros da educação infantil para o rendimento do aluno, essa perspectiva adota uma concepção restrita de educação, voltada para o desenvolvimento intelectual, e se ocupa dos meios e estratégias para estimular o crescimento dos indicadores de desempenho dos sistemas educacionais.

Essa perspectiva defende que a educação infantil, principalmente a pré-escola, deve ser provida, porque as crianças que a frequentam apresentam um desempenho acadêmico superior nas demais etapas da educação básica. Ao oferecer educação infantil, propicia-se aos indivíduos as mesmas oportunidades no início do processo para que eles sejam bem sucedidos no percurso escolar. Essa perspectiva é perversa, na medida em que atribui ao indivíduo toda a responsabilidade pelo sucesso, desconsiderando os processos de exclusão social.

O discurso que se apega a esse caráter estrito de educação tem legitimado posturas de desinteresse ou mesmo de descaso em relação às questões sociais. Pesquisas têm apontado que a educação infantil é uma estratégia importante nas políticas de redistribuição de renda, porque permite à família, e em particular às mães, exercer uma ocupação profissional, contribuindo para a melhoria da renda domiciliar per capita (MONTALI, LIMA, 2013; SORJ, 2004). As dificuldades geradas pela desigualdade e os processos de exclusão social afetam a vida de educadores e seus alunos, pois o processo educativo mobiliza um conjunto de atributos individuais e sociais que vão muito além da dimensão cognitiva. A condição de vida das crianças não pode ser negligenciada e a política educacional, não somente para as crianças de 0 a 5 anos, precisa ser formulada tendo como base uma concepção mais ampla de educação, compromissada com a dimensão social e, portanto, integrada com outros tipos de atendimento, principalmente na área da saúde e da assistência social.

Campos, em 1978, afirmava sobre a importância de se considerar a situação das famílias, em especial das mães, até porque as crianças guardam uma dependência grande da família. Nesse sentido, as alternativas de atendimento deveriam considerar a condição da criança e a situação de sua família, de modo a que as instituições de educação infantil assegurassem o cumprimento de duas funções importantes:

\footnotetext{
- a educacional propriamente dita, que responde às necessidades da criança em seus primeiros anos de vida;

- a função de guarda de filhos, que atende às necessidades da mulher que tem um emprego fora de casa e não pode se responsabilizar sozinha pelos cuidados com os filhos pequenos. (CAMPOS, 1978, p. 8)
}

Como bem observado pela autora, ao mesmo tempo em que a creche suscitou na classe média, na década de 1980, um interesse, sendo concebida como uma proposta 
aceitável, reformulou-se a motivação para que os filhos fossem matriculados nas instituições, havendo uma transição das necessidades das mães trabalhadoras para as necessidades da criança.

Embora a consideração das necessidades da criança seja uma conquista importante, a perspectiva da educação infantil como um direito social tem sido negligenciada. A Constituição Federal de 1988 define, no capítulo II, a educação como um direito social reforçando o direito dos trabalhadores urbanos e rurais, no artigo sétimo, à assistência gratuita a filhos e dependentes, desde o nascimento até cinco anos de idade, a creches e pré-escola. A educação infantil, portanto, de acordo com esse capítulo, cuja redação foi dada pela Emenda Constitucional n⿳053, de 2006, é um direito social conquistado pelos trabalhadores. Ao direito da criança à educação infantil, agrega-se o direito dos trabalhadores à assistência gratuita a seus filhos menores de 5 anos em creches e pré-escolas.

Afirmava ainda, Campos (1986), que dada a nossa forma de organização social e os padrões culturais dominantes, às famílias e, em particular, às mães, têm recaído a responsabilidade principal sobre a guarda e a educação das crianças.

\footnotetext{
Ainda que se questione este modelo, é evidente que, ao prever mecanismos que garantam à mulher igualdade de condições para exercer sua cidadania e seu direito ao trabalho, obrigatoriamente devem ser criadas formas alternativas de guarda e educação das crianças pequenas, de modo que o direito à maternidade não se choque com os demais. (CAMPOS, 1986, p.59)
}

As ideias de Campos (1986) continuam atuais, na medida em que faltam políticas sociais adequadas para a reprodução da vida familiar e o cuidado com os filhos pequenos.

Acredita-se que a recuperação de um caráter mais amplo da educação infantil como um direito social representa um grande desafio e esbarra em concepções já consolidadas na área, que reproduzem um discurso simplista dos processos históricos e sociais e explicitam uma concepção reducionista de educação.

\section{Financiamento, qualidade e demanda}

Outros desafios, de caráter mais técnico precisam ser enfrentados também. Dentre eles, o processo de formulação e implementação de políticas de educação infantil, que se relacionam com o financiamento da educação infantil, a qualidade da oferta e o atendimento à demanda.

Estudos (PINTO, 2014) têm mostrado que os municípios, embora tenham aumentado suas responsabilidades na oferta da educação básica, têm escassos recursos financeiros,, existindo uma situação de dependência significativa das transferências de recursos federais e estaduais em boa parte deles. A falta de recursos significa uma agenda de governo 
seletiva e é sabido que a educação infantil, no processo de municipalização da educação, não foi considerada prioridade, na medida em que o foco foi o ensino fundamental.

Agora, com aprovação da Lei 12.796, de 4 de abril de 2013, que instituiu a educação básica e gratuita dos 4 (quatro) aos 17 (dezessete) anos de idade, organizada em pré-escola, ensino fundamental e ensino médio, os entes federativos deveriam, até 2016, universalizar o atendimento para as crianças na faixa etária dos 4 e 5 anos, o que exige esforço considerável dos municípios que ainda não investiram nas redes de educação infantil. Sabe-se que, no Brasil, a desigualdade de atendimento é grande e está intimamente relacionada com a capacidade de financiamento, bem como de planejamento e gestão dos entes municipais. Eis, portanto, o primeiro desafio para a educação infantil.

Em relação ao segundo desafio, verifica-se, em pesquisas (CAMPOS, et al., 2010; 2011; KRAMER et al., 2014) que, quanto à qualidade do atendimento, há problemas de diferentes naturezas: pessoal não qualificado atuando como docente, prédios inadequados e mal adaptados, falta de condições adequadas na instalação que garantam o bem-estar de bebês e crianças pequenas, falta de recursos pedagógicos e brinquedos, entre outros problemas identificados em municípios brasileiros. No entanto, não são somente as condições da infraestrutura e de recursos que estão relacionados à qualidade; a estabilidade da equipe e a valorização dos profissionais de educação infantil são aspectos importantes, e o salário parece ser uma condição que se agrega aos demais fatores que impactam a qualidade do atendimento. Em pesquisa realizada pela Fundação Carlos Chagas (CAMPOS, et. al., 2011), que buscou avaliar a qualidade de 147 instituições de educação infantil em seis capitais brasileiras, verificou-se que as unidades que tiveram melhores resultados na avaliação da qualidade possuíam diretores com salários mais altos. Outro fator que se associa à qualidade é o fato de as unidades serem dirigidas por profissionais que concluíram o curso de nível superior há 15 anos ou mais e assumiram o cargo de direção por meio de concurso público, processo seletivo ou eleição (CAMPOS, et. al., 2010)

Finalmente, o terceiro desafio é a expansão de vagas para o atendimento a demanda. Até o ano de 2016, as crianças de 4 e 5 aos deverão estar matriculadas nas pré-escolas, o que exigirá esforços de muitos municípios brasileiros.

No caso das crianças de 0 a 3 anos, ainda que sua frequência às creches não seja obrigatória, há uma demanda considerável por vagas e o atendimento à população nessa faixa etária é pequeno e muito desigual nas diferentes localidades. Corre-se o risco desse atendimento ficar ainda mais prejudicado com a obrigatoriedade dos 4 e 5 anos, pois as limitações orçamentárias poderão ter efeito sobre as matrículas em creche.

A média nacional de atendimento, em 2013, foi de 87,9\% na pré-escola e de 27,9\% em creche (Todos pela Educação, 2013) ${ }^{1}$.

Considerando as metas do Plano Nacional de Educação em vigência, para os anos de 2014 a 2024, verifica-se que o atendimento em creche é pequeno e está muito aquém do 
estabelecido pela meta 1, que prevê um atendimento de $50 \%$ das crianças de 0 a 3 anos. Apesar de a legislação vigente considerar a educação infantil como direito da criança, "o Brasil convive com um limitado acesso às creches e com a reduzida qualidade da oferta existente" (GOMES, 2011, p. 11).

Já a porcentagem de atendimento da pré-escola parece razoável, no entanto, os 12\% que não estão matriculados em educação infantil significam 700 mil crianças, conforme constatou o Observatório do Plano Nacional de Educação.

Cabe destacar também que a média nacional encobre uma pronunciada desigualdade nas taxas de atendimento nas diferentes unidades da Federação. E a desigualdade de acesso na educação infantil é fortemente relacionada com desigualdades regionais e sociais, especialmente quando se considera a renda familiar das crianças atendidas.

Considerando que as famílias mais pobres são aquelas que mais dependem de políticas de proteção social e de instituições públicas de educação, o acesso restrito à educação infantil aprofunda a situação de miséria e exclusão e contribui para a persistência da desigualdade social.

\section{Considerações finais}

Os desafios indicam a necessidade de que a educação infantil seja fortalecida, tendo como horizonte a garantia do direito à educação na primeira infância, juntamente com a contemplação de todos os demais direitos relacionados com a proteção social das crianças e de suas famílias, de modo a que se promova a equidade social.

Para isso, é necessário esforço conjunto dos entes federativos, de modo a que os municípios possam reduzir os déficits de vagas em creche e atender a toda a população de 4 e 5 anos. É importante que a União exerça seu papel na coordenação da política nacional de educação, ajudando os municípios tecnicamente e financeiramente para a organização da demanda, a expansão das vagas e a melhoria da qualidade de atendimento.

As ações do MEC no âmbito da educação infantil foram muito importantes para subsidiar os municípios na implementação das políticas educação infantil, mediante a proposição de padrões de qualidade de infraestrutura para o atendimento adequado das instituições, a formação de profissionais, a garantia de alimentação escolar para as crianças atendidas em estabelecimentos públicos e conveniados, o fornecimento de material adequado às faixas etárias, o estabelecimento de padrões de qualidade para as ações de natureza pedagógica etc.

Se nas leis houve avanço significativo, resultado de lutas, conquistas, há que se avançar nas políticas implementadas, assegurando-se o direito da criança à educação, mas também à saúde, à alimentação, ao lazer, à cultura, dentre outros direitos sociais garantidos pela Constituição Federal. 
É necessário também combater os discursos escolarizantes e as perspectivas restritas de educação, recuperando o sentido de educação infantil como um direito social, que congrega os direitos da criança, mas também das famílias e dos trabalhadores.

Recebido em 14/03/2016 e aprovado em 08/06/2016

\section{Notas}

1 Informação consultada no Observatório do Plano Nacional da Educação, no endereço http://www.observatoriodopne.org.br/metas-pne/1-educacao-infantil

\section{Referências}

BRASIL. Constituição (1988) Emenda Constitucional no 59, de 11 de novembro de 2009.Brasília, DF:Diário Oficial da União, 12/11/2009, p. 8.

BRASIL. Lei n⿳0 12.796, de 05 de abril de 2013. Altera a Lei no 9.394, de 20 de dezembro de 1996, que estabelece as Diretrizes e Bases da Educação Nacional, para dispor sobre a formação dos profissionais da educação e dar outras providências.Brasília, DF: Diário Oficial da União, 05/04/2013, p. 1.

BRASIL. Lei no 9.394, de 20 de dezembro de 1996. Estabelece as Diretrizes e Bases da Educação Nacional. Brasília: Congresso Nacional, 1996. Texto atual com alterações disponível em: http://www. planalto.gov.br/ccivil_03/leis/19394.htm

CAMPOS, M. M. at al. Educação infantil no Brasil: Avaliação qualitativa e quantitativa. Relatório Final. Fundação Carlos Chagas, Banco Interamericano de Desenvolvimento, Ministério da Educação, São Paulo, 2010. Disponível em: http://www.fcc.org.br/pesquisa/eixostematicos/educacaoinfantil/pdf/ relatorio_final.pdf Acesso em 20/05/2011.

CAMPOS, M. M. et al.A gestão da Educação Infantil no Brasil (Relatório Final). São Paulo: Fundação Carlos Chagas; Fundação Victor Civita, 2011.

CAMPOS, Maria Malta; et al. A Expansão da rede de creches no município de São Paulo, durante a década de 70.v.2. São Paulo: FCC, 1988.

CAMPOS, Maria. M. A Constituinte e a educação da criança de 0 a 6 anos. Cadernos de Pesquisa, São Paulo, nº 59, p. 57-65, nov. 1986.

CAMPOS, Maria. M. M. Educação Infantil: conquistas e desafios. In: OEI. Reescrevendo a educação. Propostas para um Brasil Melhor. São Paulo: Ática, 2008. p. 91-104. Disponível em: http://oei.es/pdfs/ reescrevendo.pdf Acesso em: 30 de maio de 2014.

FERNANDES, Fabiana S. Políticas públicas e monitoramento na Educação Infantil. Estudos em Avaliação Educacional, v. 25, p. 44, 2014. 
GOHN, Maria da G. M. A Força da periferia: a luta das mulheres por creches em São Paulo. Petrópolis: Vozes, 1985.

GOMES, A. V. A. Educação Infantil: Por que mais creches? Brasília: Câmara dos Deputados, 2011. Disponível em: bd.camara.gov.br/bd/bitstream/handle/.../educacao_infantil_gomes.pdf?. Acesso em 13 de fevereiro de 2015.

KRAMER, S. et al. Gestão da Educação Infantil nas políticas municipais. Revista Brasileira de Educação, v. 19, nno 56, jan-mar. 2014.

KUHLMANN JR., M. Infância e educação infantil: uma abordagem histórica. Porto Alegre: Mediaçäo, 1998. 210p.

KULMANN JR., M. Histórias da educação infantil brasileira. Revista Brasileira de Educação, no 14, mai./ago., 2000.

MONTALI, L.; LIMA, M. T. A divisão sexual do trabalho e a desigualdade no mercado de trabalho segundo gênero: implicações para a superação da pobreza. In: VII CONGRESSO LATINO-

AMERICANO DE ESTUDOS DO TRABALHO. Mudanças e impactos e perspectivas, São Paulo, 02 a 05 de julho de 2013, p. 01-15.

NUNES, M. F. R; et al. Educação infantil no Brasil: primeira etapa da educação básica. Brasília: UNESCO, Ministério da Educação/Secretaria de Educação Básica, Fundação Orsa, 2011.

PARADA, Eugenio Lahera. Política y políticas públicas. In: SARAVIA, Henrique; FERRAREZI, Elisabete. Políticas Públicas. Brasília: ENAP, 2006, p. 67-95, volume I.

PINTO, José Marcelino Rezende. Federalismo, descentralização e planejamento da educação: desafios aos municípios. Cadernos de Pesquisa, São Paulo, 2014, vol.44, n.153, pp. 624-644. ISSN 0100-1574.

POPPOVIC, Ana Maria et al. Subsídios para elaboração de um programa nacional de atendimento às crianças de 0 até 6 anos. São Paulo: FCC, 1983. 91p.

SARAVIA, Henrique. Introdução à Teoria da Política Pública. In: SARAVIA, Henrique; FERRAREZI, Elisabete. Políticas Públicas. Brasília: ENAP, 2006, p. 21-42, volume I.

SCAVONE, D.T. de L. Marcas da história da creche na cidade de São Paulo: as lutas no cotidiano (1976-1984). Dissertação (mestrado). Programa de Pós-Graduação em Educação, Universidade São Francisco, Itatiba, 2011.

SORJ, B. Trabalho e Responsabilidades Familiares: um estudo sobre o Brasil. (Relatório Final). Rio de Janeiro: UFRJ, 2004.

SOUZA, Celina. Políticas Públicas, uma revisão de literatura. Sociologia, Porto Alegra, ano 8, n. 16, jul/dez 2006, p. 20-45.

SPOSATI, Aldaíza. Vida Urbana e Gestão da Pobreza. Cortez Ed., 333 pp. São Paulo, 1988.

TORRES, Pedro Medellín. La política de las políticas públicas: propuesta teórica y metodológica para el estudio de las políticas en países de frágil institucionalidad. Santiago de Chile: CEPAL, 2004. Disponível em: http://www.cepal.org/publicaciones/xml/5/15555/sps93_lc1270.pdf. Acesso em 15 de janeiro de 2014. 